\title{
Somatic RET mutation in a patient with pigmented adrenal pheochromocytoma
}

\author{
Nicole Maison, Esther Korpershoek', Graeme Eisenhofer ${ }^{2}$, Mercedes Robledo ${ }^{3}$, \\ Ronald de Krijger ${ }^{1,4}$ and Felix Beuschlein \\ Endocrine Research Unit, Medizinische Klinik und Poliklinik IV, Klinikum der Universität München, Munich, \\ Germany, \\ ${ }^{1}$ Department of Pathology, Erasmus MC Cancer Institute, University Medical Center Rotterdam, Rotterdam, \\ The Netherlands, \\ ${ }^{2}$ Department of Medicine III, Institute of Clinical Chemistry and Laboratory Medicine, Technische Universität \\ Dresden, Dresden, Germany, \\ ${ }^{3}$ Hereditary Endocrine Cancer Group, Human Cancer Genetics Programme, Spanish National Cancer Research Centre \\ (CNIO) and ISCIII Center for Biomedical Research on Rare Diseases (CIBERER), Madrid, Spain \\ ${ }^{4}$ Department of Pathology, Reinier de Graaf Hospital, Delft, The Netherlands
}

Correspondence should be addressed to $\mathrm{F}$ Beuschlein

Email

Felix.Beuschlein@ med.uni-muenchen.de

\section{Summary}

Pheochromocytomas (PCC) and paraganglioma (PGL) are rare neuroendocrine tumors arising from chromaffin cells of the neural crest. Mutations in the RET-proto-oncogene are associated with sporadic pheochromocytoma, familial or sporadic medullary thyroid carcinoma (MTC) and multiple endocrine neoplasia type 2. In the past, only few cases of pigmented PCCs, PGLs, and one case of pigmented MTC have been reported in the literature. Herein, we present the case of a 77-year old woman with a history of Tako-tsubo-cardiomyopathy and laboratory, as well as radiological, high suspicion of pheochromocytoma, who underwent left-sided adrenalectomy. The $3 \mathrm{~cm}$ tumor, which was located on the upper pole of the left adrenal, appeared highly pigmented with dark red to black color. Histologic examinations revealed highly pleomorphic cells with bizarre, huge hyperchromatic nuclei, that immunohistochemically were positive for chromogranin A and synaptophysin, focally positive for HMB45 and negative for melan A. These clinical and pathological features led to the diagnosis of the rare variant of a melanotic 'black' pheochromocytoma. In our case a somatic RET mutation in exon 16 (RET c.2753T > C, p.Met918Thy) was detected by targeted next generation sequencing. In summary, this case represents a rare variant of catecholamine-producing tumor with distinct histological features. A potential relationship between the phenotype, the cellular origin and the genetic alterations is discussed.

\section{Learning points:}

- Pheochromocytoma is a rare neuroendocrine tumor.

- Pigmentation is seen in several types of tumors arising from the neural crest. The macroscopic black aspect can mislead to the diagnosis of a metastasis deriving from a malignant melanoma.

- RET mutation are seen in catecholamine and non-catecholamine producing tumors of the same cellular origin.

\section{Background}

This case represents a rare variant of catecholamineproducing tumor with distinct histological features. A potential relationship between the phenotype, the cellular origin and the genetic alterations is discussed.

\section{Case presentation}

A 77-year-old patient with a history of arterial hypertension, intermittent atrial fibrillation and an episode of Takot-tsubo-cardiomyopathy presented for pre-surgical evaluation of suspected catecholamine excess. 


\section{Investigation}

Repeated laboratory examinations documented elevated plasma and urine metanephrine (urine metanephrine $6205.88 \mu \mathrm{g} / 24 \mathrm{~h}(<699.66 \mu \mathrm{g} / 24 \mathrm{~h})$, normethanephrine $4013.1 \mu \mathrm{g} / 24 \mathrm{~h}(<1698.06 \mu \mathrm{g} / 24 \mathrm{~h})$ and plasma metanephrine $1460.16 \mathrm{pmol} / 1(<465.3 \mathrm{pmol} / \mathrm{l})$, normetanephrine $1116.72 \mathrm{pmol} / \mathrm{l}(<982.8 \mathrm{pmol} / \mathrm{l}))$. A combined ${ }^{18} \mathrm{~F}$-DOPAPET/CT scan revealed presence of a clearly DOPA-positive (SUVmax 7,8) lesion considered to be arising from the left adrenal gland, measuring $3.0 \times 3.3 \mathrm{~cm}$ (Fig. 1).

\section{Pathologic findings}

The resected tumor measured $3.5 \times 3.2 \times 2.2 \mathrm{~cm}$ and weighed $37 \mathrm{~g}$ including adjacent adrenal tissue. The tumor was relatively well demarcated with macroscopically red to black color, surrounded by a thin golden-yellow rim representing the preexistent adrenal cortex. Histological slides showed compact groups of cells, partly with huge bizarre, hyperchromatic cell nuclei, and pigment inclusions within the granular cytoplasm. Because of the macroscopical appearance there was initial suspicion of malignant melanoma but in consideration of the clinically and radiologically clear indication of pheochromocytoma, additional immunohistochemical analyses were performed. Tumor cells showed an intense expression of chromogranin A and synaptophysin, S100 was positive only in sustentacular cells (Fig. 2A, B, C and D). HMB45, a marker of melanosomes showed focal

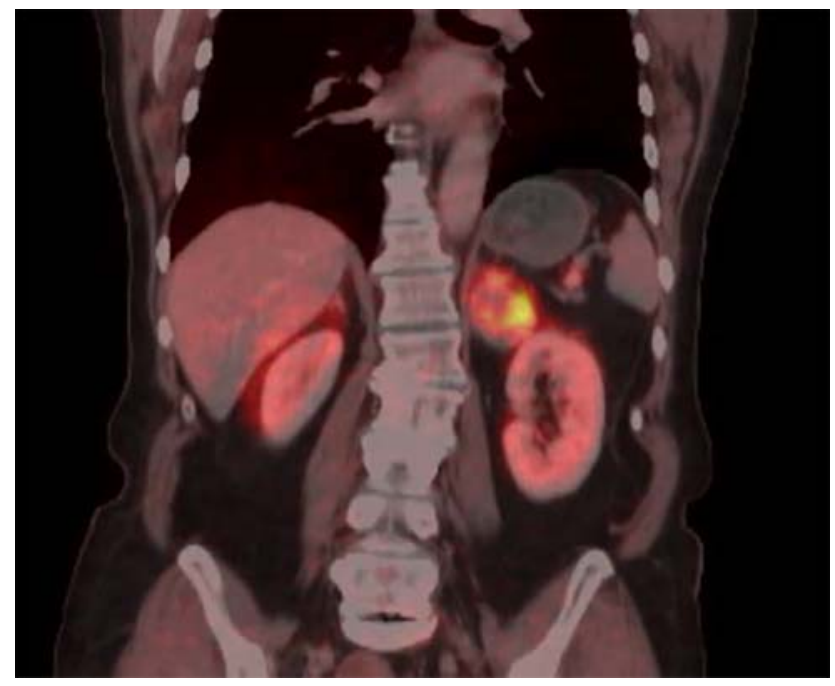

\section{Figure 1}

Combined DOPA-PET/CT scan of the abdomen showing an intensively DOPA-positive lesion on the upper left kidney pole.

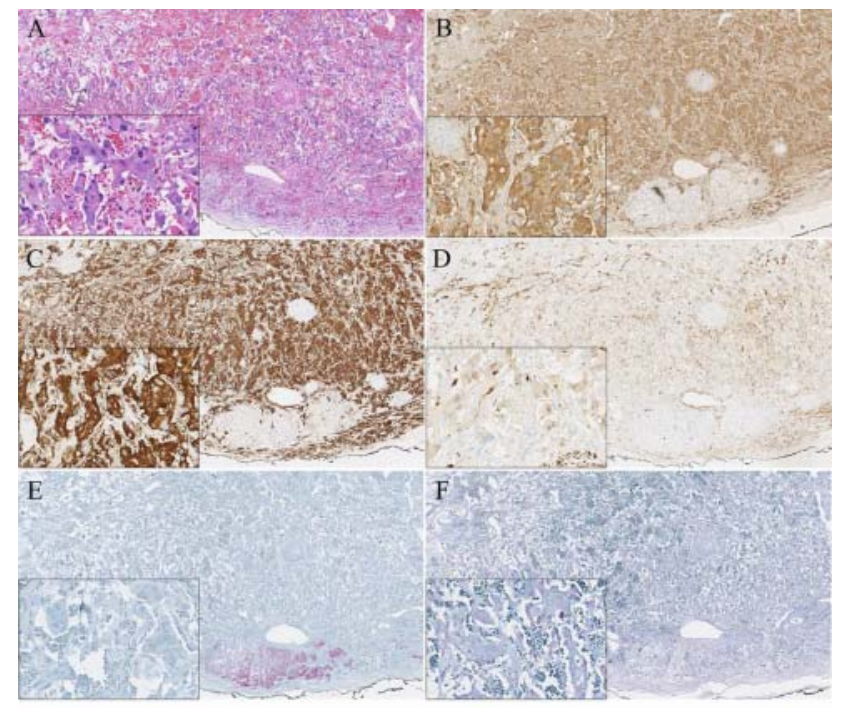

\section{Figure 2}

The hematoxylin eosin staining (A) shows highly vascularized tumor tissue, composed of highly pleomorphic, basophilic tumor cells. The positive staining of chromogranin A (B) and synaptophysin (C) of the tumor cells and the presence of S100 positive cells (D) surrounding the tumor cells, confirms this tumor is a pheochromocytoma. Melan-A staining is negative in the tumor cells (E), while the remaining cortex stains positive. HMB45, a marker for melanosomes, shows focal positive cytoplasmic staining (F).

positive cytoplasmic staining (Fig. 2F) and Melan A was negative (Fig. 2E). These features led to the final diagnosis of a melanotic pheochromocytoma (Fig. 3).

Targeted next generation sequencing including EPAS1, FH, HRAS, KIF1B, MAX, MDH2, MEN1, NF1, RET, SDHA, SDHAF1, SDHAF2, SDHB, SDHC, SDHD, TMEM127 and $V H L$ was done on the tumor DNA, which revealed a somatic RET mutation in exon 16 (RET c.2753T $>$ C, p.Met918Thy), further validated by Sanger sequencing. An underlying MEN2 syndrome was excluded by sequencing the germline DNA.

\section{Treatment}

The patient was treated preoperatively with alpha blockade and underwent uneventful left-sided laparoscopic adrenalectomy. After a short recovery period the patient was discharged from the hospital without need for antihypertensive medication.

\section{Outcome and follow-up}

Follow-up examinations 3 and 6 month after surgery revealed normalization of plasma catecholamines. 


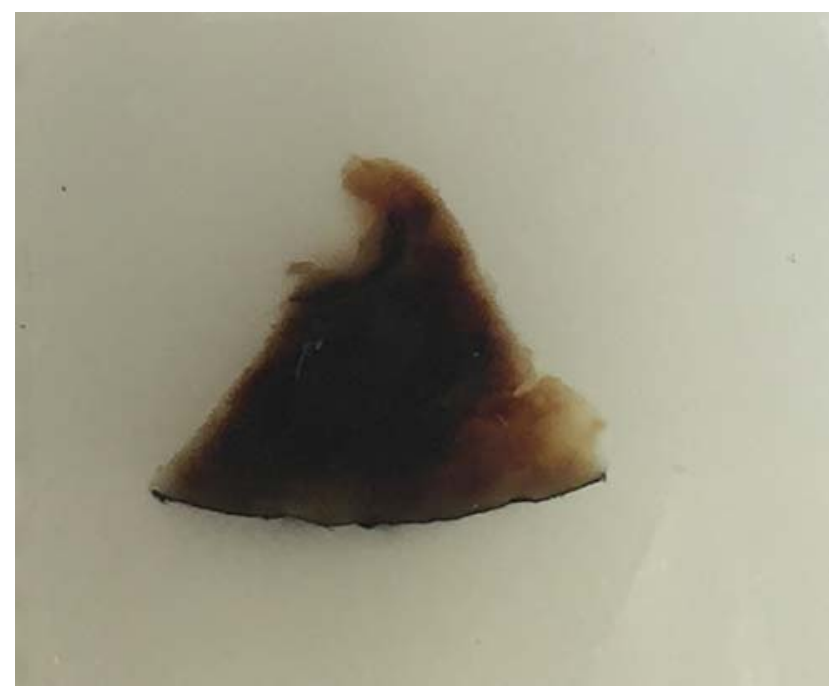

Figure 3

Macroscopic aspect of the resected tumor (following paraffin embedding).

Following current guideline suggestions yearly follow-up examinations were recommended (1).

The patient was enrolled into the registry and biobank of the European Network for the Study of Adrenal Tumors (www.ensat.org) upon written informed consent.

\section{Discussion}

Similar to other reports in the literature the black pigmentation of the tumor first led to the suspicion of a metastasis deriving from a malignant melanoma. In fact, black pheochromocytomas (PCC) are very rarely found. In a well defined sub-cohort of $766 \mathrm{PCC} /$ paraganglioma (PGL) patients registered in the ENSAT registry (from Munich, Rotterdam, Madrid, Dresden and Paris) this is the first reported case of a 'black' pheochromocytoma. In the literature, only 18 cases of pigmented PGL and one macroand 11 microscopically pigmented pheochromocytomas have been reported (Table 1), which emphasizes the rareness of this finding. However, several cases of pigmented tumors, (2), (3) among which neuroblastomas, schwannomas or adrenocortical adenoma, had been described in the past. Ikeda et al. (4) reported a case of an medullary thyroid carcinoma (MTC) with a PGL-like pattern and melatonin production. The tumor showed the PGL-typical 'sustentacular cells' as well as pigmented dendritic cells. Genetic analysis unfortunately is not available in this case.

Reported histopathological results regarding the pigment differed, but in most cases lipofuscin, true melanin and neuromelanin were found (5). In our case, the positive

Table 1 Previous case reports of pigmented pheochromocytoma and pigmented paraganglioma.

\begin{tabular}{|c|c|c|c|c|c|}
\hline Reference & Case No. & $\begin{array}{c}\text { Macroscopic } \\
\text { pigment }\end{array}$ & $\begin{array}{c}\text { Microscopic } \\
\text { pigment }\end{array}$ & Location & Mutation \\
\hline \multicolumn{6}{|c|}{ Pigmented pheochromocytoma } \\
\hline Landas et al. (7) & 6 & & 6 & & \\
\hline Chetty et al. (8) & 3 & & 3 & & \\
\hline Langer et al. (9) & 1 & & 1 & & \\
\hline Bellezza et al. (10) & 1 & 1 & & & \\
\hline Handa et al. (11) & 1 & & 1 & & \\
\hline Present case & 1 & 1 & & & \\
\hline \multicolumn{6}{|c|}{ Pigmented paraganglioma } \\
\hline Stout (1935) & 1 & & & Ganglion nodosum & NR \\
\hline Tavassoli (12) & 2 & & & Uterus & NR \\
\hline Paulus et al. (13) & 1 & & & Orbit & NR \\
\hline Hofmann et al. (14) & 1 & & & Posterior mediastinum & NR \\
\hline Küchemann (15) & 1 & & & Retroperitoneum & NR \\
\hline Moran et al. (16) & 5 & & & $\begin{array}{l}\text { Bladder, spine }(2), \\
\text { anterior mediastinum, } \\
\text { retroperitoneum }\end{array}$ & NR \\
\hline Lack et al. (5) & 1 & & & Retroperitoneum & NR \\
\hline Mikolaenko et al. (17) & 1 & & & Heart & NR \\
\hline Dundr et al. (18) & 1 & & & Urinary bladder & NR \\
\hline Reddy et al. (19) & 1 & & & Vagal trunk & NR \\
\hline Miraldi et al. (20) & 1 & & & Heart & NR \\
\hline Gonnella et al. (21) & 1 & & & Heart & NR \\
\hline Petramala et al. (22) & 1 & & & Heart & $S D H B$ \\
\hline Zhao et al. (23) & 1 & & & Kidney & NR \\
\hline
\end{tabular}

NR, not reported. 
HMB45 staining indicates that the pigment results from the presence of melanosomes in at least some of the tumor cells. While true melanin is a pigment produced by melanocytes from L-DOPA, neuromelanin and lipofuscin are byproducts of the macro-autophagy pathway and are associated with breakdown of mitochondria (lipofuscin) and metabolism of catecholamines (neuromelanin) (5). Neuromelanin can also be found in neurons of the substantia nigra. Sulzer et al. (6) have shown that L-DOPA induced elevation of cytosolic dopamine is responsible for extended neuromelanin biosynthesis. Thus, neuromelanin and lipofuscin are probably related to excessive catecholamine oxidation. It is suggestive that the tumor cells in pheochromocytoma would contain neuromelanin rather than melanin, also because they possess the enzymes (L-DOPA) to produce it. However, a clear distinction between melanin and neuromelanin cannot be drawn by immunohistochemical staining procedures alone.

The somatic RET mutation found in our case is of interest as also non-catecholamine producing but MEN2 associated tumors such as MTC have been reported to occur as hyperpigmented. The rareness of this association clearly indicates that RET mutations are not sufficient to cause a hyperpigmentation phenotype. However, it is of interest, that melanocytes, C-cells and adrenal medullary cells share common embryogenetic origins from the neural crest. This common ancestry could be the basis for shared morphological features during tumor development. However, as pigmentation is not an usual feature in non-melanotic tumors, other molecular factors seem to be necessary to induce this particular phenotype.

\section{Summary}

A 'black,', hyperpigmented, adrenal pheochromocytoma is a very rare variant of a catecholamine producing tumor which in the presented case was associated with the presence of melanosomes in tumor cells and the presence of somatic RET mutation. As pigmentation has also been described in non-catecholamine-producing tumor cells originating from the neural crest, such as MTC, common mechanisms for pigmentation in these tumor entities could be considered.

\section{Declaration of interest}

The authors declare that there is no conflict of interest that could be perceived as prejudicing the impartiality of the research reported.

\section{Funding}

This research did not receive any specific grant from any funding agency in the public, commercial or not-for-profit sector.

\section{Patient consent}

We confirm that written informed consent has been obtained from the patient.

\section{Author contribution statement}

$\mathrm{N}$ Maison was the patient's physician and was involved in paper writing; E Korpershoek conducted the pathology review; G Eisenhofer was responsible for catecholamine determinations; $M$ Robledo conducted genetic studies; R de Krijger conducted the pathology review; F Beuschlein was the patient's physician, and was responsible for the study supervision and paper writing.

\section{References}

1 Lenders JW, Duh QY, Eisenhofer G, Gimenez-Roqueplo AP, Grebe SK, Murad MH, Naruse M, Pacak K, Young WF, Jr \& Endocrine Society 2014 Pheochromocytoma and paraganglioma: an endocrine society clinical practice guideline. Journal of Clinical Endocrinology and Metabolism 99 1915-1942. (doi:10.1210/jc.2014-1498)

2 Curras-Freixes M, Inglada-Pérez L, Mancikova V, Montero-Conde C, Letón R, Comino-Méndez I, Apellániz-Ruiz M, Sánchez-Barroso L, Aguirre Sánchez-Covisa M, Alcázar V et al. 2015 Recommendations for somatic and germline genetic testing of single pheochromocytoma and paraganglioma based on findings from a series of 329 patients. Journal of Medical Genetics 52 647-656. (doi:10.1136/jmedgenet-2015-103218)

3 Donis-Keller H 1995 The RET proto-oncogene and cancer. Journal of Internal Medicine 238 319-325. (doi:10.1111/j.1365-2796.1995. tb01205.x)

4 Ikeda T, Satoh M, Azuma K, Sawada N \& Mori M 1998 Medullary thyroid carcinoma with a paraganglioma-like pattern and melanin production: a case report with ultrastructural and immunohistochemical studies. Archives in Pathology and Laboratory Medicine 122 555-558.

5 Lack EE, Kim H \& Reed K 1998 Pigmented ("black") extraadrenal paraganglioma. American Journal of Surgical Pathology 22 265-269. (doi:10.1097/00000478-199802000-00018)

6 Sulzer D, Mosharov E, Talloczy Z, Zucca FA, Simon JD \& Zecca L 2008 Neuronal pigmented autophagic vacuoles: lipofuscin, neuromelanin, and ceroid as macroautophagic responses during aging and disease. Journal of Neurochemistry 106 24-36. (doi:10.1111/j.1471-4159.2008. 05385.x)

7 Landas SK, Leigh C, Bonsib SM \& Layne K 1993 Occurrence of melanin in pheochromocytoma. Modern Pathology 6 175-178.

8 Chetty R, Clark SP \& Taylor DA 1993 Pigmented pheochromocytomas of the adrenal medulla. Human Pathology 24 420-423. (doi:10.1016/ 0046-8177(93)90091-T

9 Langner C, Hoffmann JG, de Geeter P, Rompel R \& Rüschoff J 2001 Pigmented pheochromocytoma. Case report with immunohistochemical and electron microscopic characterization. Der Pathologe 22 276-280. (doi:10.1007/s002920100465)

10 Bellezza G, Giansanti M, Cavaliere A \& Sidoni A 2004 Pigmented "black" pheochromocytoma of the adrenal gland: a case report and review of the literature. Archives in Pathology and Laboratory Medicine 128 e125-e128. 
11 Handa U, Khullar U \& Mohan H 2005 Pigmented pheochromocytoma: report of a case with diagnosis by fine needle aspiration. Acta Cytologica 49 421-423. (doi:10.1159/000326176)

12 Tavassoli FA 1986 Melanotic paraganglioma of the uterus. Cancer 58 942-948. (doi:10.1002/1097-0142(19860815)58:4<942::AIDCNCR2820580423>3.0.CO;2-T)

13 Paulus W, Jellinger K \& Brenner H 1989 Melanotic paraganglioma of the orbit: a case report. Acta Neuropathologica 79 340-346. (doi:10.1007/ BF00294673)

14 Hofmann WJ, Wöckel W, Thetter O \& Otto HF 1995 Melanotic paraganglioma of the posterior mediastinum. Virchows Archiv 425 641-646. (doi:10.1007/BF00199354)

15 Kuchemann K 1995 A rare case of pigmented paraganglioma. Virchows Archiv 427 111-112. (doi:10.1007/BF00203746)

16 Moran CA, Albores-Saavedra J, Wenig BM \& Mena H 1997 Pigmented extraadrenal paragangliomas. A clinicopathologic and immunohistochemical study of five cases. Cancer 79 398-402. (doi:10.1002/ (SICI)1097-0142(19970115)79:2 < 398::AID-CNCR24>3.0.CO;2-V)

17 Mikolaenko I, Galliani CA \& Davis GG 2001 Pigmented cardiac paraganglioma. Archives in Pathology and Laboratory Medicine 125 680-682.
18 Dundr P, Dudorkinová D, Povýsil C, Pesl M, Babjuk M, Dvorácek J \& Zelinka T 2003 Pigmented composite paraganglioma-ganglioneuroma of the urinary bladder. Pathology, Research and Practice 199 765-769. (doi:10.1078/0344-0338-00495)

19 Reddy CE, Panda NK, Vaiphei K \& Powari M 2003 Pigmented vagal paraganglioma. Journal of Laryngology and Otology 117 584-587. (doi:10.1258/002221503322113102)

20 Miraldi F, Taffon C, Toscano M \& Barretta A 2007 Black cardiac paraganglioma in a multiple paraganglioma syndrome. European Journal of Cardio-Thoracic Surgery 32 940-942. (doi:10.1016/j.ejcts.2007. 08.026)

21 Gonnella C, Messa FC, Confessore P \& Greco C 2008 Angiographic evidence of pigmented cardiac paraganglioma. Journal of Cardiovascular Medicine 9 319. (doi:10.2459/JCM.0b013e32801411d1)

22 Petramala L, Cotesta D, Filetti S \& Letizia C 2009 Pigmented 'black' cardiac paraganglioma in a patient with a novel germ-line SDHD mutation. European Journal of Cardio-Thoracic Surgery 35189. (doi:10.1016/j.ejcts.2008.10.007)

23 Zhao L, Luo J, Zhang H \& Da J 2012 Pigmented paraganglioma of the kidney: a case report. Diagnostic Pathology 7 77. (doi:10.1186/17461596-7-77)

Received in final form 13 January 2016

Accepted 18 January 2016 